\title{
Technical and economic issues of reconfiguration of a coal-fired district heating source
}

\author{
Mariusz Tańczuk ${ }^{*}$,Eligiusz Olszewski, and Alfred Goluzda \\ Energetyka Cieplna Opolszczyzny SA, ul. Harcerska 15, 45-118 Opole, Poland
}

\begin{abstract}
District heating technologies should comply with forthcoming strict regulations on emissions and energy effectiveness. The majority of the communal district heating systems in Poland still produce heat in coalfired boilers that are in many cases worn out and operated with low efficiency, which particularly occurs during off-season time. The paper deals with possible solutions for improving efficiency of coal-fires heat generating plants due to its reconfiguration by applying new heat generating facilities or new fuels - alternative to coal. The work concerns repowering the existing conventional heat generating plant according to chosen scenarios of the plant configuration meeting technical and environmental requirements forecasted for the year of 2035. The maximum demand for heat of the system supplied by the plant is $185 \mathrm{MW}$. Annual load of the particular units in analyzed plant, including cogeneration facility based on IC-engines and gas or steam turbines have been projected and interfacing of the units has been analyzed and discussed. Taking into account different technical configurations on one side, and different energy and fuel prices on the other side, the comparative cost-benefits analysis of the assumed scenarios has also been made.
\end{abstract}

\section{Introduction}

Despite the current changes in the world energy sector as well as the upcoming strategies for the period 2020-2050 [1], inefficient energy systems, including district heating (DH) systems, often based on solid fuels, mainly coal, still continue to dominate in the structure of the electricity and heat production systems in certain countries of the world, including countries in Europe [2]. Such systems require actions to increase efficiency of energy conversion processes, meet growing environmental concerns and to become more economically attractive.

Improving the district heating systems has become a tendency in Europe since at least 20 years. It is worth mentioning that such systems across Europe are differentiated by the technology, temperature of water and delivery extent as well as by the resources used for heat (and electricity) generation. Compared to other European countries, particularly these located in western and northern part of Europe, the coal is a dominant energy source in

* Corresponding author: mtanczuk@ecosa.pl 
Central and East Europe DH applications. According to [3] district heating systems supply with heat around $29 \%$ of residential buildings in that region. An interesting and worth attention case is Poland with $41 \%$ share of DH systems [4] and in the same time with coal as a main source of input energy of heat generating plants. The hard coal remains dominant resource for decades, however its share in heat production is expected to go down as stated in long-term forecasts available in [5].

One of the most common DH solutions for managing the current and upcoming conditions is to apply repowering plants with the CHP, usually gas-fired systems. It can help with meeting growing restrictions in the dust, $\mathrm{NO}$ and sulfur dioxide $\left(\mathrm{SO}_{2}\right)$ emissions - as presented in Figure 1, as well as the $\mathrm{CO}_{2}$ limitations which are very cost-creative.
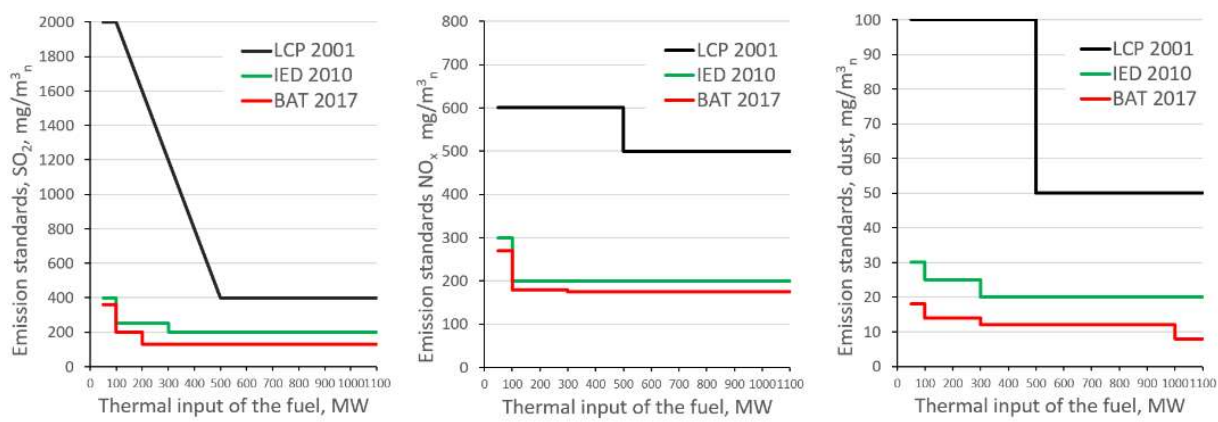

Fig. 1. Emission standards in 2001, 2010 and 2017 - for large combustion plants.

Another positive effect of reconfiguration of the plants and starting necessary investment actions is solving the problem of technical wear of the existing boilers as well as improving efficiency of production of heat in the summer time.

The paper presents issues connected with the technical and economic efficiency of reconfiguration of a coal-fired municipal heat generating plant as a source of DH system. The alternative configuration has been proposed and the optimization analysis of the plant modernization by installing new units or repowering existing ones, including CHP systems is the subject of the paper.

\section{Current DH plant configuration}

The investigation concerns retrofitting the existing conventional heat generating plant according to eight different scenarios of the plant configuration meeting technical and environmental requirements forecasted for the year of 2035. The existing plant is a heat source for high temperature municipal district heating system with the maximum demand for heat reaching $185 \mathrm{MW}$. The hot water of nominal pressure $\mathrm{p}_{\mathrm{n}}=1.6 \mathrm{MPa}$ and nominal (maximum) supply temperature $\mathrm{t}_{\mathrm{s}, \mathrm{n}}=150^{\circ} \mathrm{C}$ is a heat carrier in the system.

The plant consists of the following heat generating units:

- one pulverized hard coal-fired water boiler PCB (labelled as WP120) with the nominal heat capacity $125 \mathrm{MW}$,

- two hard coal stoker-fired water boilers SCB (labelled as WR25 no. 1 and. 2) with the nominal heat capacity $33 \mathrm{MW}$ each,

- high-efficient cogeneration unit based on a gas turbine unit GTU fired with natural gas of a nominal electric capacity 7.4 MW and integrated with a heat recovery boiler HRB of a nominal heat capacity 14.7 MW,

- high efficient cogeneration unit based on a steam turbine STU supplied with hard coal stoker-fired steam boiler SSCB (labelled as OR50) of a steam capacity $50 \mathrm{t} / \mathrm{h}$. 
The STU cogeneration unit is integrated with a steam-water heat exchanger and reaches the nominal thermal capacity $29 \mathrm{MW}$ and nominal electric capacity 10.7 MW. In the heatonly operation mode, thermal capacity increases up to $40 \mathrm{MW}$. Apart from the described units, there is also additional production facility installed in the plant:

- one pulverized hard coal-fired water boiler PCB (labelled as WR40) - of $40 \mathrm{MW}$ of thermal capacity remaining permanently disconnected from the plant infrastructure,

- one gas boiler of $25 \mathrm{MW}$ of thermal capacity installed as a peak-load unit.

The schematic diagram of the existing plant is shown in Figure 2. The total installed heat capacity of the analyzed plant reaches almost $260 \mathrm{MW}$ (without $40 \mathrm{MW}$ of disconnected boiler). The total electricity power output equals to $18.1 \mathrm{MW}$.

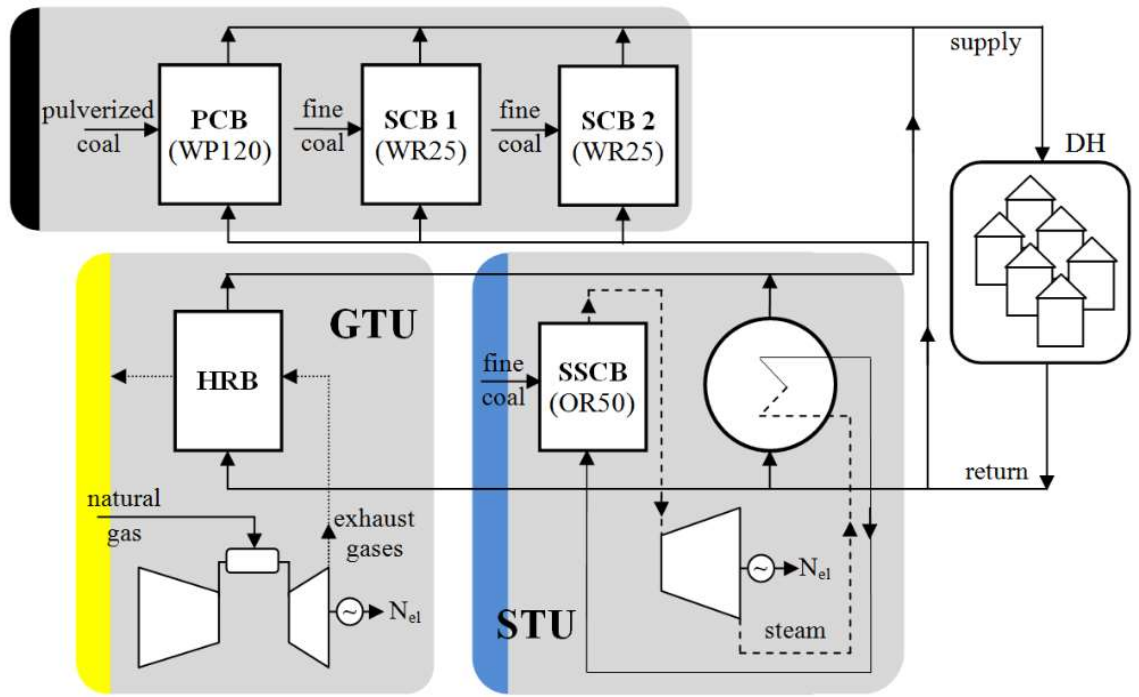

Fig. 2. Schematic diagram of the current configuration of analyzed DH plant.

The load duration curve of the district heating system supplied by the plant is presented in the Figure 3.

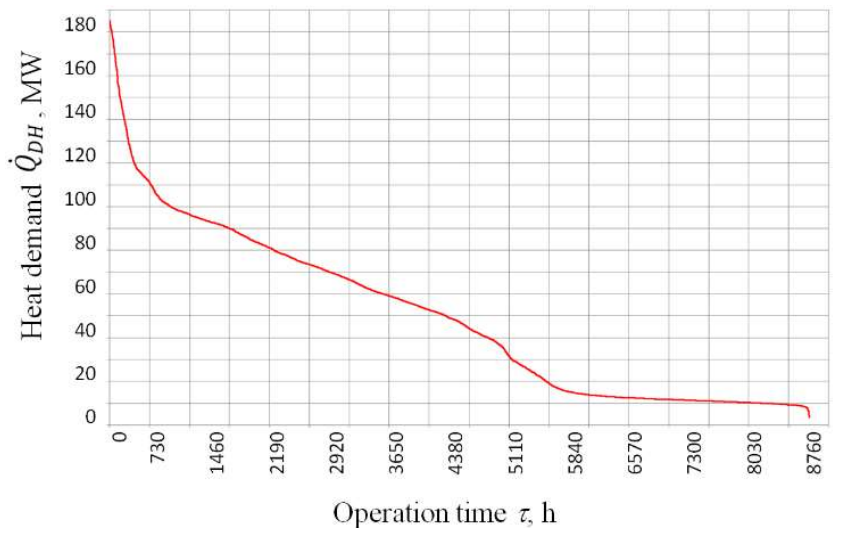

Fig. 3. The load duration curve of the analyzed DH plant.

The annual energy production of the plant reaches $1582 \mathrm{TJ}$ of heat and $106 \mathrm{GWh}$ of electricity, while total demand for chemical energy equals to $2298 \mathrm{TJ}$. As it can be seen in the Figure 3, the plant remains under operation during the whole year time supplying city 
DH system with heat in order to provide central heating of residential buildings (in the heating season) and domestic hot water (in the season and off-season). The difference between maximum demand in the winter time that equals $185 \mathrm{MW}$ and rather constant demand during off-season (around $15 \mathrm{MW}$ ) is significant. Lower summer demand for heat often leads to low efficiency of production due to the reduced boiler load. One of the measure to improve such inconvenience is installing optimal sized CHP unit operated at the base of the load duration curve.

\section{Methodology of analysis}

The evaluation of technoeconomic analysis of reconfiguration of the existing DH plant has been made for a chosen scenarios, according to input data presented in Table 1.

Table 1. Main design parameters of the units used for plant configuration.

\begin{tabular}{|c|l|c|c|c|}
\hline No. & \multicolumn{1}{|c|}{ Unit } & $\begin{array}{c}\text { Max./min. } \\
\text { thermal } \\
\text { output, MW }\end{array}$ & $\begin{array}{c}\text { Nominal } \\
\text { electric } \\
\text { output, MW }\end{array}$ & $\begin{array}{c}\text { Nominal } \\
\text { efficiency, \% }\end{array}$ \\
\hline 1 & Pulverized coal-fired water boiler PCB & $120 / 55$ & - & 91.5 \\
\hline 2 & Coal stoker-fired water boilers SCB 1 & $33 / 10$ & - & 84.3 \\
\hline 3 & Coal stoker-fired water boilers SCB 2 & $33 / 10$ & - & 84.3 \\
\hline 4 & Coal stoker-fired steam boiler SSCB & $40 / 20$ & - & 85.0 \\
\hline 5 & Back-presure steam turbine STU & - & 10.7 & 29.0 \\
\hline 6 & STU turbine heat exchanger & $29 / 7$ & - & - \\
\hline 7 & Coal stoker-fired water boilers SCB 3 & $40 / 10$ & - & 85.0 \\
\hline 8 & Gas turbine unit GTU with HRB boiler & $13.5 / 13.5$ & 7.0 & 82.0 \\
\hline 9 & Gas boiler & $25 / 5$ & - & 92.0 \\
\hline 10 & Biomass stoker-fired steam boiler BB & $13.7 / 7.6$ & - & 82 \\
\hline 11 & Extraction-condensing steam turbine & - & 6.7 & 31.0 \\
\hline 12 & Pulverized coal-fired water boiler PCB 2 & $81 / 32$ & - & 91.5 \\
\hline 13 & Gaseous ICE-based CHP - 5 units & $5 \times 3.5 / 0.7$ & $5 \times 4.5$ & 83.5 \\
\hline
\end{tabular}

In each of the analysed cases, the analysis consists of two stages: thermodynamic evaluation and economic evaluation. The basis for the thermodynamic evaluation was the heat load duration curve (Fig. 3) given as an input data for the analysis. The energy balance calculations were conducted for each eight investigated configuration scenarios where assumed units of a given size and given efficiency was composed in heat generating DH plant. Analysis has been carried out with use of hourly optimization method [6].

The design parameters of the units presented in Table 1 are in particular a result of assumed reconfiguration scenarios, described in Table 2. On the basis of assumed technical configurations of the plant and in accordance with design parameters of applied units as well as with given load duration curve, hour by hour simulation of plant annual operation has been conducted for each of the scenario. In the result, the annual heat and electricity production in the plant was derived with use of the following formulas: 


$$
\begin{aligned}
& Q_{u_{i}}=\int_{\tau=0}^{\tau=876}\left(\dot{Q}_{u_{i}}\right) \mathrm{d} \tau \\
& N_{e l, u_{i}}=\int_{\tau=0}^{\tau=876}\left(\dot{N}_{e l, u_{i}}\right) \mathrm{d} \tau
\end{aligned}
$$

where $Q_{u_{i}}$ is the annaul heat production by the particular unit i, $\dot{Q}_{u_{i}}$ is the current heat capacity of the unit i provided by the simulation procedure, $N_{e l, u_{i}}$ is the annaul electricity production of the particular unit i, $\dot{N}_{e l, u_{i}}$ is the current electric power output of the unit i provided by the simulation procedure and $\tau$ is time, in hours.

\begin{tabular}{|c|c|}
\hline Scenario & Desciption \\
\hline $\mathrm{S} 1$ & $\begin{array}{l}\text { based on the current configuration of the plant (Fig. 1) with no retrofitting actions, } \\
\text { taking into account only the necessary maintenance and modernization work due to } \\
\text { technical condition of units and environmental restrictions (necessity of construction of } \\
\text { flue gas desulphurisation and denitrification) }\end{array}$ \\
\hline $\mathrm{S} 2$ & $\begin{array}{l}\text { current configuration of the plant extended by the additional cogeneration unit with } \\
\text { biomass steam boiler BB and extraction steam turbine }\end{array}$ \\
\hline S3 & $\begin{array}{l}\text { based on S2 configuration with GTU unit removed and with steam turbine unit STU } \\
\text { operated at the base load }\end{array}$ \\
\hline S4 & $\begin{array}{l}\text { current configuration of the plant with PCB replaced by currently disconnected } \\
\text { repowered SCB3, peak-load gas boiler in use }\end{array}$ \\
\hline S5 & current configuration of the plant with PCB replaced by repowered PCB2 \\
\hline S6 & $\begin{array}{l}\text { current configuration of the plant with additional CHP block installed on the basis of } 5 \\
\text { ICE-based gaseous units, with steam turbine unit STU operated at the base load }\end{array}$ \\
\hline S7 & based on S6 configuration but with ICE unites operated at the base load \\
\hline S8 & based on S6 configuration with GTU unit removed \\
\hline
\end{tabular}

Table 2. Analyzed reconfiguration scenarios.

The thermodynamic evaluation was the basis for further economic optimisation procedure which was carried out to find the optimal configuration of the DH plant regarding the economic feasibility. The economic evaluation bases in this case on discounted method, with Net Present Value (NPV) as the result of the calculations. The chosen method is widely used in cost-effective designs [7], lifetime optimisation [8] and in comparative techno-economic analysis [9]. To determine the NPV index, cash flow parameter $C F$ is used [10], in accordance with the following formula:

$$
N P V(t=N)=-J_{0}+\sum_{t=1}^{N} \frac{C F_{t}}{(1+d)^{t}}
$$

where $t$ is the time of operation in years, $N$ is assumed lifetime of the project expressed in years, $J_{0}$ is the total investment outlays in particular scenario, $C F_{t}$ - annual cash flow calculated for each scenario (in EUR), $d$ - rate of discount.

Apart from NPV index, the applied method enables to calculate also Net Present Value Ratio (NPVR) indicator which is expressed by the equation:

$$
N P V R=\frac{N P V}{J_{0}}
$$




\subsection{Input data and assumptions for economic evaluation}

To calculate the value of the annual cash flow CF it was necessary to adopt economic assumptions and additional data. The most important of them are:

- investment outlays for each scenario, specified in Table 3,

- the price of hard coal: $13.90 \mathrm{PLN} / \mathrm{GJ}$,

- the price of biomass: 21 PLN/GJ,

- the price of natural gas: $83 \mathrm{PLN} / \mathrm{MWh}$,

- the price of carbon dioxide $\mathrm{CO}_{2}$ allowances: $7 \mathrm{EUR} / \mathrm{Mg} \mathrm{CO}_{2}$.

- the sales price of heat: $41 \mathrm{PLN} / \mathrm{GJ}$,

- the sales price of electricity: $150 \mathrm{PLN} / \mathrm{MWh}$,

- the price of gaseous cogeneration tags (yellow tags): 110 PLN/MWh,

- the price of solid fuel cogeneration tags (red tags): 10 PLN/MWh,

- the price of renewable tags (green tags): 100 PLN/MWh,

Table 3. Investment outlays $J_{0}$ for analyzed scenarios.

\begin{tabular}{|c|c|c|c|}
\hline Scenario & Outlays, mln PLN & Scenario & Outlays, mln PLN \\
\hline S1 & 51.3 & S5 & 132.2 \\
\hline S2 & 81.3 & S6 & 97.3 \\
\hline S3 & 81.3 & S7 & 97.3 \\
\hline S4 & 55.0 & S 8 & 97.3 \\
\hline
\end{tabular}

The further, additional assumptions have been also made, as follows:

- operation period of the system: $\mathrm{N}=18$ years,

- priority in the production of electricity for the internal load of the heat generating plant is taken into consideration, excess quantities are sold,

- quantitative data regarding the production and sales in the subsequent years of the operation of the system are derived from the calculations performed in the thermodynamic evaluation,

- discount rate $d$ equals to $8.0 \%$.

\section{Results and discussion}

As a result of the research the hourly simulations for each considered DH plant scenario were conducted. On the basis of simulation the quantitative data needed for further economic analysis were obtained.

Table 4 summarizes the annual demand for fuel in the analyzed configuration cases and the annual quantity of heat and electricity production in each DH plant scenario. It also contains $\mathrm{CO}_{2}$ emissions calculated during the evaluation. It is worth noting that much less $\mathrm{CO}_{2}$ emissions occur in case of biomass scenarios ( $\mathrm{S} 2$ and $\mathrm{S} 3$ ). The positive effect of cogeneration should be emphasized for ICE modules scenarios (S6 to S8): in these cases the share of electricity production is significantly larger compared to other configuration alternatives.

Table 5 contains results of economic evaluation. NPV indexes in last year of the assumed operation time ( $\mathrm{N}=18$ years) for each scenario have been related to the NPV of scenario S1, assumed as a baseline scenario. The same approach has been applied for NPVR indicator. Final results have also been presented in the Figure 4.

As it can be concluded both from the Table 5 and Figure 4, the highest feasibility, regarding both criteria, NPV and NPVR, occurs for scenarios where CHP units based on 
natural gas-fired ICE modules are implemented. NPV to NPV 1 ratio in these cases stands above $100 \%$, while for the weakest scenario (S5) hardly reaches 30\%. Results gained for S8 case show that cutting off gas turbine unit from ICE-based scenario lowers profitability of the project: NPV ratio goes down by around 5\% noticed in scenario S6 or even by $15 \%$ of scenario S6. NPVR indicators confirm results drown on the basis of NPV indexes.

Table 4. Quantitative annual operation data of each analyzed plant configuration scenario.

\begin{tabular}{|c|c|c|c|c|c|c|}
\hline Scenario & $\begin{array}{c}\text { Heat } \\
\text { generation, } \\
\text { GJ }\end{array}$ & $\begin{array}{c}\text { Electricity } \\
\text { generation, } \\
\text { MWh }\end{array}$ & $\begin{array}{c}\text { Demand } \\
\text { for coal, } \\
\mathbf{M g}\end{array}$ & $\begin{array}{c}\text { Demand for } \\
\text { natural gas, } \\
\text { MWh }\end{array}$ & $\begin{array}{c}\text { Demand for } \\
\text { biomass, Mg }\end{array}$ & $\begin{array}{c}\text { CO2 } \\
\text { emission, } \\
\text { kg/MWh }\end{array}$ \\
\hline S1 & 1571317 & 106037 & 78642 & 149397 & 0 & 367 \\
\hline S2 & 1571317 & 102750 & 59135 & 140140 & 44704 & 292 \\
\hline S3 & 1571317 & 68502 & 69385 & 0 & 50333 & 300 \\
\hline S4 & 1570249 & 106037 & 79106 & 152162 & 0 & 370 \\
\hline S5 & 1571317 & 106037 & 77719 & 149397 & 0 & 363 \\
\hline S6 & 1571317 & 200316 & 66569 & 362528 & 0 & 333 \\
\hline S7 & 1571317 & 238109 & 56498 & 484061 & 0 & 314 \\
\hline S8 & 1571317 & 177642 & 76153 & 260957 & 0 & 349 \\
\hline
\end{tabular}

Table 5. Results of the technoeconomic analysis related to scenario S1.

\begin{tabular}{|l|c|c|c|c|c|}
\hline No. & NPV( 18)/NPVs1(18) & NPVR/NPVRs1 & No. & NPV( 18)/NPVs1(18) & NPVR/NPVRs1 \\
\hline S1 & $100 \%$ & $100 \%$ & S5 & $65 \%$ & $25 \%$ \\
\hline S2 & $85 \%$ & $54 \%$ & S6 & $112 \%$ & $59 \%$ \\
\hline S3 & $91 \%$ & $57 \%$ & S7 & $103 \%$ & $54 \%$ \\
\hline S4 & $101 \%$ & $95 \%$ & S & $103 \%$ & $53 \%$ \\
\hline
\end{tabular}

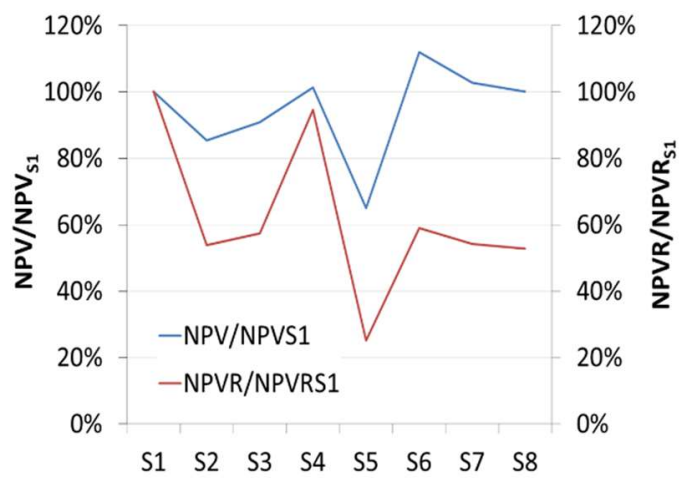

Fig. 4. NPV(18) and NPVR(18) indexes derived for analyzed scenarios - presented in relation to the baseline scenario $\mathrm{S} 1$. 


\section{Conclusions}

The presented study is an example of how the proper configuration of the plant supplying district heating system may positively affect the feasibility of the plant operation. The calculations conducted for the basic economic assumptions showed higher profitability of the cases with natural gas-fired ICE cogeneration modules installed in the plant.

On the basis of the presented results, the following final conclusions can be made:

- projecting the configuration of the district heating plant requires good prediction on electricity and fuels' prices,

- configuration of the system should always be preceded by thermal and economic optimization,

- retrofitting coal-based DH plant by the cogeneration units fuelled with natural gas may be the solution for on-going changes in environmental and energy efficiency regulations,

- implementation of the biomass district heating facilities in coal-based DH systems can improve feasibility under expected legislative conditions.

\section{References}

1. European Commission, "A roadmap for moving to a competitive low carbon economy in 2050," Brussels, 2011.

2. M. Tańczuk, J. Skorek, P. Bargiel, Energy Convers. Manage. 149 (2017)

3. Intelligent Energy Europe Programme. Energy Efficiency Trends and Policies in the EU an analysis based on the ODYSSEE and MURE databases (2015)

4. Euroheat \& Power, http://euroheat.org, 2017 [accessed 15 May 2017]

5. District Heating and Cooling Country by Country. 2015 Survey. Euroheat \& Power.

6. M. Pavičević, T. Novosel, T. Pukšec, N. Duić, Energy (2017) https://doi.org/10.1016/j.energy.2017.06.105 (In Press)

7. A. Vlysidis, M. Binns, C. Webb, C.A. Theodoropoulos, Energy Convers. Manage. 103 (2015)

8. A. Nemet, J.J. Klemes, Z. Kravanja, Energy 57 (2013)

9. M. Wzorek, M. Tańczuk, Waste Manage. Res. 33, 7 (2015)

10. J. Kalina Energy Convers. Manage. 51 (2010) 